TITLE:

\title{
Nonlinear vibration isolator with adjustable restoring force
}

$\operatorname{AUTHOR}(\mathrm{S})$ :

Araki, Yoshikazu; Asai, Takehiko; Kimura, Kosuke; Maezawa, Kosei; Masui, Takeshi

\section{CITATION:}

Araki, Yoshikazu ...[et al]. Nonlinear vibration isolator with adjustable restoring force. Journal of Sound and Vibration 2013, 332(23): 60636077

ISSUE DATE:

2013-11

URL:

http://hdl.handle.net/2433/178666

\section{RIGHT:}

(C) 2013 Elsevier Ltd.; This is not the published version. Please cite only the published version.; この論文は出版社版でありません。引用の際に は出版社版をご確認ご利用ください。 
2

3

4

5

6

7

8

9

\title{
Nonlinear vibration isolator with adjustable restoring force
}

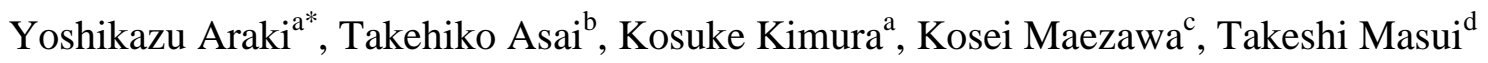 \\ ${ }^{a}$ Department of Architecture and Architectural Engineering, Kyoto University, Katsura, \\ Nishikyo, Kyoto 615-8540, Japana \\ ${ }^{\mathrm{b}}$ Department of Civil and Environmental Engineering, University of Illinois at \\ Urbana-Champaign, 205 N. Mathews Ave., Urbana, IL 61801, USA \\ ${ }^{\mathrm{c}}$ Hojo Structure Research Institute, Kawaracho, Chuo, Osaka 541-0048, Japan \\ ${ }^{\mathrm{d}}$ Department of Architecture, Kansai University, Yamatecho, Suita, Osaka 564-8680, Japan \\ *Email Address: araki@archi.kyoto-u.ac.jp (Yoshikazu Araki)
}

\section{Abstract}

This paper presents a vertical quasi-zero stiffness (QZS) vibration isolator with a mechanism for adjusting restoring force. QZS vibration isolators have high initial stiffness and QZS around the static equilibrium position. This way, excessive deformation due to self-weight can be avoided while having enough vibration reduction capability to dynamic excitations. One of the main issues left for QZS vibration isolators is the difficulty in keeping the vibration reduction capability when the vibration isolated object is replaced. In such a case, adjustment of its restoring force becomes necessary in accordance with the self-weight of the newly placed vibration isolated object. This paper attempts to address this issue by proposing a mechanism that enables quick and easy adjustment of the restoring force of a QZS vibration isolator. The proposed mechanism consists of cranks and a screw jack. With the present 
25 mechanism, the restoring force provided by horizontally placed springs can be

26 converted into the vertical restoring force of the vibration isolator. In the conversion, the

27 vertical resisting force can be adjusted simply by applying and removing torque to the screw jack to change and hold the angle of inclined bars placed in the cranks. In this study, a prototype of a class of QZS vibration isolator having the proposed mechanism is produced. Shaking table tests are performed to demonstrate the efficacy of the present mechanism, where the produced prototype is subjected to various sinusoidal and earthquake ground motions. It is demonstrated through the shaking table tests that the produced prototype can reduce the response acceleration within the same tolerance even when the mass of the vibration isolated object is changed.

Keywords: nonlinear vibration isolator; vertical vibration isolator; constant-force spring; adjustable restoring force

\section{Introduction}

40 Passive vibration isolation has been an active area of research, and a variety of passive

41 vibration isolators have been developed so far. For horizontal vibration isolation, low

42 stiffness elements such as springs are installed between the base of a vibration isolator 
43 and the objects to be isolated. The low stiffness elements prevent vibration energy from

44 being transmitted into the isolated object. On the other hand, if low stiffness elements

45 are used for vertical vibration isolation, large deformations take place due to the self-weight of the isolated objects. This makes vertical vibration isolation much more difficult than horizontal vibration isolation.

To overcome the difficulty, quasi-zero-stiffness (QZS) vibration isolators have been studied for many years [1-25]. QZS vibration isolators are designed so that their restoring forces satisfy the following two conditions: (1) initial stiffness, which resists self-weight, is large, and (2) the tangent stiffness, which resists dynamic load, is close to zero around the static equilibrium position. This way, transmission of vibration energy due to dynamic load can be prevented while excessive deformation due to self-weight can be avoided. In most QZS vibration isolators, such nonlinear restoring forces are realized by effective use of geometric nonlinearity [1-22]. In the past studies, magnets

$56[23,24]$ or shape memory alloys [25] were also used to obtain such nonlinear restoring forces.

One of the main issues left for the QZS vibration isolators is the difficulty in adjusting their restoring forces to the change of the self-weight, or the mass, of the

60 isolated object. When the mass changes, it is necessary for the QZS vibration isolators 
61 to adjust their restoring force by, e.g., replacing springs. The use of balance weight is

62 another way of dealing with the mass change. In either case, it is not easy and takes

63 considerable time for the adjustment of the nonlinear restoring force of a QZS vibration

64 isolator. To the authors' knowledge, however, no studies have addressed this issue.

This study presents a QZS vibration isolator with a mechanism that enables easy and quick adjustment of its nonlinear restoring force. In this paper, first, a mechanism is proposed to change the nonlinear restoring force. Also presented is a combination of the proposed mechanism and a vertical vibration isolator with flag-shaped restoring force, which belongs to a class of QZS vibration isolators and was proposed in the authors' previous work $[26,27]$. To show the efficacy of the present mechanism, a prototype of the proposed vibration isolator is produced to perform quasi-static and dynamic loading tests. Numerical simulations are also conducted to compare the test and simulation results with theoretical predictions.

\section{Mechanisms}

\subsection{Mechanism for adjusting restoring force}

Figure 1(a) illustrates a schematic view of the present vibration isolator. As shown in

Figure 1(b), the proposed isolator is divided into three portions. The upper portion is a 
79 table on which the isolated objects are placed. The upper portion consists of one

80 horizontal top plate and two vertical hexagonal plates. The middle portion is composed

81 of two shafts connected by elements to provide a nonlinear restoring force.

82 Constant-force springs, coil springs, and wires are examples of such elements. Here,

83 constant-force springs are composed of rolled spring steel and have constant restoring

84 force regardless of their stretch [26,27]. At both ends of each shaft, inner and outer

85 roller bearings are installed. In the lower portion, one screw jack, two linear bushes, and

86 four cranks are attached to the base plate. Here, the screw jack and the linear bushes are

87 connected by two beams. The beams are connected to the cranks using pin connections.

88 Half of the length of the screw jack is threaded in the opposite direction to that of the

89 other half. The distance between the two beams can be changed by rotating the screw

90 jack while keeping the geometry of the mechanism symmetric. The positions of the

91 beams are automatically locked simply by removing the torque applied to the screw jack.

92 This way, the angle of the inclined bar in each crank can be changed and held simply by

93 applying and removing the torque to the screw jack. As depicted in Figure 1(a), the

94 inclined sides of the hexagonal plates are placed on the inner bearings of the shafts, and the outer bearings of the shafts are placed on the inclined bars of the cranks. With such a

96 composition, the horizontal restoring force provided by the middle portion can be 
97 converted into the vertical restoring force. In the conversion, furthermore, the vertical resisting force can be adjusted simply by changing the angle of the inclined bars of the cranks, which is the key ingredient of the present vibration isolator. restoring force $n$ provided by the middle portion shown in Figure 2 is derived below.

Figures 2(b) and 2(c), let the angles of bar $\mathrm{AB}$ and the inclined side of the upper table be $\theta$ and $\gamma$, respectively, with respect to the vertical. Figure 3 illustrates the internal forces acting on the right shaft shown in Figure 2(b). Figure 3(a) illustrates the internal

shows the internal force acting on each outer bearing from inclined bar $\mathrm{AB}$ of the crank.

As shown in Figure 3(c), the force-balance equation in the horizontal direction for the shaft can be written as

$$
n=\frac{1}{2}\left(\frac{1}{\tan \theta}+\frac{1}{\tan \gamma}\right) f .
$$

111 Assume that the mass of the shaft is negligibly small. Then, Eq. (1) is valid even under dynamic condition. Thus, the amplification factor $\alpha$ is defined as

$$
\alpha(\theta)=\frac{f}{n}=\frac{2}{1 / \tan \theta+1 / \tan \gamma} .
$$

114 Figure 2(c) illustrates the schematic view of a crank. Bars AB and AE are connected by 
115 a pin at point $\mathrm{A}$. Bars $\mathrm{CD}$ and $\mathrm{AB}$ are also connected by a pin at point $\mathrm{D}$. Bar $\mathrm{AE}$ is

116 connected rigidly to the base plate at point $\mathrm{E}$. The lengths of $\mathrm{AD}, \mathrm{AE}$, and $\mathrm{CD}$ are $r, s$,

117 and $l$, respectively. Let $h$ indicate the distance between point $\mathrm{C}$ and the base plate. Let

118 the distance between point $\mathrm{C}$ and bar $\mathrm{AE}$ be $d$, which is the key variable to adjust $\theta$.

119 Then, the geometric relationship between $\theta$ and $d$ is

$$
l^{2}=(d+r \sin \theta)^{2}+(s-h-r \cos \theta)^{2} .
$$

121 Suppose that $d$ is given. Then, $\theta$ can be calculated by solving Eq. (3), and $\alpha$ can be obtained by substituting the calculated $\theta$ into Eq. (2).

\subsection{Mechanism for flag-shaped restoring force}

Figure 4 shows a mechanism for providing a flag-shaped restoring force [26,27]. The

relative vertical displacement between the upper table and the base is defined as $u$,

whose positive direction is contraction. The relative displacement between the two

shafts is defined as $w$, whose positive direction is extension. Figure 4(a) depicts the position where the upper table is at the upper limit of the stroke of the vibration isolator.

130 At this position, both $u$ and $w$ are set as $u=w=0$. Figures 4(b) illustrates the static equilibrium position when an object is placed on the upper table, where $u=u_{s e}$ and

$132 w=w_{\text {se }}$. Here, $m$ denotes the mass of the object and $g$ indicates the gravitational 
133 acceleration. Figure 4(c) illustrates the position where the upper table reaches the lower

134 limit of the stroke, where $u=u_{\max }$ and $w=w_{\max }$.

In the following, the variation of $n$ is considered when $w$ is increased from 0 to

$w_{\max }$. When $w=0$, the restoring force $n$ changes from 0 to $N_{1}$, where $N_{1}$ is the sum of the

capacities of constant-force springs $1 \mathrm{a}$ and $1 \mathrm{~b}$. At all the positions when $0<w<w_{\max }$, both

the other hand, constant-force spring 2, which is connected to the shafts via a coil spring

and a wire in series, provides a restoring force between 0 and $N_{2}$, where $N_{2}$ denotes the

capacity of constant-force spring 2 . When $w$ is small, no restoring force is provided by

When the upper tables moves downward beyond the position where the wire sag stops

to take place, the length of the coil spring changes linearly with respect to $w$. The present vibration isolator is designed so that the static equilibrium position lies in this linear range. Here, the coil spring is used to avoid high frequency accelerations caused by sudden, or discontinuous, change of the restoring force. When the upper table moves downward further and exceeds the position where the restoring force of the coil spring reaches $N_{2}$, the restoring force provided by constant-force spring 2 becomes $N_{2}$. In this case, $n$ is expressed as $n=N_{1}+N_{2}$. 
152 illustrate the shifts of axes. In this paper, $\Delta(\bullet)$ indicates that the reference position 153 of the variable is the static equilibrium position. More specifically, $\Delta f, \Delta n, \Delta u$, and $\Delta w$ are defined as

$$
\Delta f=f-m g, \Delta n=n-m g / \alpha, \Delta u=u-u_{s e}, \Delta w=w-w_{s e} .
$$

Such shifts of axes are introduced here to consider the vibration around the static equilibrium position. Figure 5(c) depicts the geometric relationship between $u$ and $w$ when the upper table is moved downward while the base is fixed. The thicker line indicates the upper side of bar $\mathrm{AB}$, and the thinner lines indicate the inclined side of the upper table before and after the movement. From this figure, the geometric relationship can be written as

$$
u=\frac{1}{2}\left(\frac{1}{\tan \gamma}+\frac{1}{\tan \theta}\right) w=\frac{1}{\alpha} w .
$$

Figure 6(a) shows the relationship between the shifted restoring force $\Delta n_{N F}$ and the shifted relative displacement $\Delta w$, where no friction is assumed. Let $k$ be the stiffness of the coil spring. Then, the relationship can be written as

$$
\Delta n_{N F}=n_{N F}-\frac{m g}{\alpha}=\left\{\begin{array}{ccc}
N_{1}-m g / \alpha & \text { if } & -w_{s e}<\Delta w<w_{L} \\
k \Delta w & \text { if } & \Delta w_{L} \leq \Delta w \leq \Delta w_{U} \\
N_{1}+N_{2}-m g / \alpha & \text { if } & w_{U}<\Delta w<w_{\max }-w_{s e}
\end{array},\right.
$$

where 


$$
\Delta w_{U}=\left(N_{1}+N_{2}-m g / \alpha\right) / k, \Delta w_{L}=\left(N_{1}-m g / \alpha\right) / k .
$$

Figure 6(b) illustrates the relationship between the friction force $q$ and $\Delta \dot{w}$ assuming

Coulomb's friction [28]. Here, the overdot indicates the differentiation with respect to

time. The friction force $q$ can be written as

$$
q=\left\{\begin{array}{ccc}
-Q & \text { if } & \Delta \dot{w}<0 \\
0 & \text { if } & \Delta \dot{w}=0 \\
Q & \text { if } & \Delta \dot{w}>0
\end{array} .\right.
$$

Then the shifted restoring force $\Delta n$ including Coulomb's friction can be written as

$$
\Delta n(\Delta w, \Delta \dot{w})=\Delta n_{N F}(\Delta w)+q(\Delta \dot{w})
$$

Figure 7 illustrates this relationship. The restoring force curve shown in Figure 7(c) is

called as "flag-shaped restoring force" because the shape of the restoring force curve in the region of $\Delta n>0$ and $\Delta w>0$ looks like a flag [29].

$$
\Delta f=\alpha \Delta n
$$

And, from Eq. (5), the relationship between $\Delta u$ and $\Delta w$ can be written as

$$
\Delta u=\frac{1}{\alpha} \Delta w .
$$

From Eqs. (10) and (11), $\Delta f$ can be written as

$$
\Delta f(\Delta u, \Delta \dot{u})=\left\{\begin{array}{ccc}
\alpha\left(N_{1}+q(\alpha \Delta \dot{u})\right)-m g & \text { if } & -u_{s e}<\Delta u<w_{L} / \alpha \\
\alpha^{2} k \Delta u+\alpha q(\alpha \Delta \dot{u}) & \text { if } & w_{L} / \alpha \leq \Delta u \leq w_{U} / \alpha \\
\alpha\left(N_{1}+N_{2}+q(\alpha \Delta \dot{u})\right)-m g & \text { if } & w_{U} / \alpha<\Delta u<u_{\max }-u_{s e}
\end{array},\right.
$$


184 Note that, when $m g$ changes, $\alpha$ should be adjusted so that the following inequality

$$
\alpha\left(N_{1}+Q\right)<m g<\alpha\left(N_{1}+N_{2}-Q\right) \text {, or } \frac{m g}{N_{1}+N_{2}-Q}<\alpha<\frac{m g}{N_{1}+Q}
$$

holds to make the vibration isolator self-centering, or to make the upper table return to

the static equilibrium position when the external force other than the gravity force is removed.

The strengths of the present mechanism and the flag-shaped restoring force can be

summarized as follows:

1. The use of constant-force springs allows the mechanism to have a long stroke of more than several centimeters while keeping the mechanism compact. motion.

3. The flag-shaped restoring force provides the isolator with the self-centering capability. This is because static equilibrium can be achieved only at the origin of

2. Existence of plateau in the restoring force curve limits the response acceleration within a specified tolerance regardless of the amplitude and frequency of an input the restoring force curve. The self-centering capability prevents the displacement from accumulating in one direction in vibration, which may be seen when friction damping is applied [29].

4. The flag-shaped restoring force avoids resonance. The proposed isolator responses 
linearly in the neighborhood of the static equilibrium point. In this linear range, the problems because the displacement amplitude of interest in this paper is well beyond the linear range. Even if resonance takes place in the linear range, the equivalent natural frequency (computed either by the secant stiffness or by the tangent stiffness) decreases significantly as the displacement amplitude increases beyond the linear range. The change of the equivalent natural frequency with respect to the displacement amplitude avoids resonance.

212 As pointed out in Section 2.2, one of the key features of the present vibration isolator is

213 that it can limit the response acceleration within a specified tolerance regardless of the

214 magnitude and frequency of an input motion. This subsection presents basic equations

215 for this feature. Suppose that the vibration isolator is subject to the (absolute) ground

216 acceleration $\ddot{u}_{g}$. Then, the equation of motion for the present vibration isolator can be

written as

$$
m\left(\Delta \ddot{u}+\ddot{u}_{g}\right)+c \Delta \dot{u}+\Delta f(\Delta u, \Delta \dot{u})=0 .
$$

219 Assume that the vibration isolator is designed so that $c$ is negligibly small. Then, from 
220 Eqs.(8), (12), and (14), the magnitude of the absolute response acceleration $\left|\Delta \ddot{u}+\ddot{u}_{g}\right|$

221 can be bounded as

$$
\left|\Delta \ddot{u}+\ddot{u}_{g}\right| \leq h(\alpha)
$$

where

$$
h(\alpha)=\max \left(g-\frac{\alpha}{m}\left(N_{1}-Q\right), \frac{\alpha}{m}\left(N_{1}+N_{2}+Q\right)-g\right) .
$$

225 From Eqs. (15) and (16), it can be said that the proposed vibration isolator can specify

226 the peak response accelerations by adjusting $\alpha / m$. This implies that the present

vibration isolator can reduce the peak response acceleration to the same value by adjusting the amplification factor $\alpha$ when $m$ is changed. Consider the range of variation of $h(\alpha)$ when $\alpha$ changes in the range of Eq. (13). Both $g-\alpha\left(N_{1}-Q\right) / m$ and $\alpha\left(N_{1}+N_{2}+Q\right) / m-g$ are linear functions of $\alpha$, and hence $h(\alpha)$ is a piecewise linear function of $\alpha$. The range of variation of $h(\alpha)$ can be obtained as

$$
\frac{N_{2} / 2+Q}{N_{1}+N_{2} / 2} g \leq h(\alpha)<\frac{N_{2}}{N_{1}+Q} g
$$

234 It should be noted here that, from Eqs. (15) to (17), the response acceleration can be

235 reduced to less than $N_{2} g /\left(N_{1}+Q\right)$ regardless of $m$ as far as the assumptions made in 236 this section are valid. 


\section{3. Experiments}

239

242

\subsection{Prototype design}

Figure 8 shows a photograph of a prototype of the present vibration isolator produced for testing the effectiveness of the proposed mechanisms. The height of the vibration isolator at the static equilibrium position is about $400 \mathrm{~mm}$. To suppress the rocking response of the upper table, 2 plates are fixed with pin connections to each side of the vibration isolator. Note that, although the screw jack is rotated by hand in the present prototype of the vibration isolator, it is possible to use a combination of sensing devices and an electric motor to rotate the screw jack for sensing the mass change and adjusting the restoring force automatically.

The parameters for the mechanism for the flag-shaped restoring force are as follows. The nominal values of $N_{1}$ and $N_{2}$ are $235.5 \mathrm{~N}$ and $31.4 \mathrm{~N}$, respectively, and that of $k$ is $1.5 \mathrm{~N} / \mathrm{mm}$. It is difficult to determine the value of $Q$ prior to the quasi-static loading tests because friction takes place at many locations. Hence, as explained later in Section 3.2, the reference value of $Q$ is determined as $6.8 \mathrm{~N}$ from the quasi-static loading tests. Substituting these values into Eq. (17), the theoretical prediction of the upper bound of the response acceleration can be obtained as $0.13 \mathrm{~g}$.

The parameters for the mechanism for changing the restoring force are provided 
256 as $\tan \gamma=1.6, l=150 \mathrm{~mm}, r=75 \mathrm{~mm}$, and $s-h=150 \mathrm{~mm}$. Figure 9 shows the

257 relationship between the amplification factor $\alpha$ and $d$. Here, recall that $d$ is the

258 distance between point $\mathrm{C}$ and bar $\mathrm{AE}$ as shown in Figure 2. Table 1 shows the reference

259 values that define the amplified restoring forces, where $N_{1(\alpha)}, N_{2(\alpha)}, Q_{(\alpha)}, u_{R(\alpha)}$, and

$k_{(\alpha)}$ are defined as

261

$$
N_{1(\alpha)}=\alpha N_{1}, \quad N_{2(\alpha)}=\alpha N_{2}, Q_{(\alpha)}=\alpha Q, \quad u_{R(\alpha)}=\frac{w_{U}-w_{L}}{\alpha}, k_{(\alpha)}=\alpha^{2} k
$$

\subsection{Quasi-static loading tests}

264 To obtain the parameters for constructing a numerical model of the proposed vibration

isolator, quasi-static loading tests are carried out. The quasi-static loading tests are

performed by changing the value of $d$ parametrically from $15 \mathrm{~mm}$ to $65 \mathrm{~mm}$ with an

increment of $5 \mathrm{~mm}$. In each quasi-static loading test, forced displacement is applied to the upper table manually. The origin is set to the equilibrium position for each test. The displacement of the upper table is obtained by using non-contact laser displacement sensors. The restoring force $f$ is obtained by the load cells inserted between the ground and the base of the vibration isolator.

Figure 10(a) shows the restoring force curves obtained from the quasi-static 
274 for the region of $-50 \mathrm{~mm}<\Delta u<50 \mathrm{~mm}$ while the applied displacement amplitude of

$275 \Delta u$ was more than $50 \mathrm{~mm}$. From the figure, it is clear that the restoring force is

276 amplified by adjusting the value of $d$. Figure 10(b) shows the numerical models of the

277 restoring force curves, where $S_{1(\alpha)}$ and $S_{2(\alpha)}$ are the upper and lower values of the

278 restoring force when $\Delta u \leq-u_{R(\alpha)} / 2$, and $S_{3(\alpha)}$ and $S_{4(\alpha)}$ are the values when

$279 u_{R(\alpha)} / 2 \leq \Delta u$. Table 2 summarizes the values of the parameters that determine the

280 flag-shaped restoring force. The procedure used for determining these values is

281 summarized as follows:

282 1. The values of $S_{1(\alpha)}$ and $S_{2(\alpha)}$ are determined by averaging the upper and lower values of the restoring force curve, respectively, in the range of in the range of $u_{R(\alpha)} / 2 \leq \Delta u \leq 50 \mathrm{~mm}$.

2. The amplified capacities $N_{1(\alpha)}$ and $N_{2(\alpha)}$ are obtained as

$$
N_{1(\alpha)}=\frac{S_{1(\alpha)}+S_{2(\alpha)}}{2}, \quad N_{2(\alpha)}=\frac{S_{3(\alpha)}+S_{4(\alpha)}}{2}-N_{1(\alpha)} .
$$

$$
k_{(\alpha)}=\frac{N_{2(\alpha)}}{u_{R(\alpha)}} .
$$


4. The amplified friction force $Q_{(\alpha)}$ is determined by

$$
Q_{(\alpha)}=\frac{\left(S_{1(\alpha)}-S_{2(\alpha)}\right)+\left(S_{3(\alpha)}-S_{4(\alpha)}\right)}{2} .
$$

The experimentally observed restoring force curves shown in Figure 10(a) are not so

smooth as their numerical models shown in Figure 10(b) because it is difficult to realize such ideal restoring force curves shown in Figure 9(b) due to many factors. Uncertainty of the restoring force provided by the constant-force springs is one of the main reasons. such ideal restoring force curves. experimentally. Good agreement can be seen between these values. In Figure 12, the cross mark plots the relationship between $N_{1(\alpha)}$ and $Q_{(\alpha)}$, both of which are obtained from the experiments. The solid line shows the linear relationship

$$
Q_{(\alpha)}=\beta N_{1(\alpha)},
$$

where the value of $\beta$ is obtained by the least-squares fit as 0.029 . The reference value $Q_{(\alpha)}$ shown in Table 1 is obtained by multiplying the obtained value of $\beta$ and the nominal value of $N_{1(\alpha)}$. 
309 Figure 13 illustrates the configuration of the experimental setup. Only vertical ground

310 motions are applied to the vibration isolator. To investigate the vibration reduction

311 capability of the present vibration isolator when the mass of the isolated object is

312 changed, shaking table tests are performed for the cases of $d=60,40$, and $20 \mathrm{~mm}$.

313 These values correspond to the amplification factor $\alpha$ of $1.25,1.57$, and 1.91, and the

314 mass $m$ of $32.0 \mathrm{~kg}, 40.2 \mathrm{~kg}$, and $49.0 \mathrm{~kg}$, respectively. Acceleration sensors are installed

315 on the upper table of the vibration isolator to measure response acceleration (RA), and

316 on the shaking table to record ground acceleration (GA). Non-contact laser

317 displacement sensors are fixed to a measurement frame to measure response absolute

318 displacement (RAD) and ground displacement (GD). Response relative displacement

319 (RRD) is obtained by subtracting GD from RAD. The primary natural frequencies in the

320 neighborhood of the static equilibrium position are $2.74,3.26$, and $3.68 \mathrm{~Hz}$ for the cases

321 of $d=60,40$, and $20 \mathrm{~mm}$, respectively. These values are obtained from the free

vibration measurements.

Table 3 summarizes input excitations. The input waves are 2, 3, 4, 5, and $6 \mathrm{~Hz}$ sine waves, and the vertical, or up-down (UD), component of the earthquake ground motion recorded at K-NET Ojiya station in Japan during the 2004 Mid Niigata 
and $0.50 \mathrm{~g}$ for $2 \mathrm{~Hz}$ sine wave, $0.25 \mathrm{~g}, 0.50 \mathrm{~g}, 0.75 \mathrm{~g}$, and $1.00 \mathrm{~g}$ for $3,4,5$, and $6 \mathrm{~Hz}$

UD earthquake ground motion, whose PGA is $0.83 \mathrm{~g}$. measured in the shaking table tests. Due to the limitations of the capability of the shaking table, there are small differences between the intended and the measured PGAs.

Figure 14 compares the PRAs with the PGAs. As can be observed in Table 4 and Figure 14, the PRAs are reduced to under $0.2 \mathrm{~g}$ for all the sine waves except the case of $d=20$ $\mathrm{mm}$ and S4-4 input. On the other hand, the PRAs were dropped to under $0.15 \mathrm{~g}$ for all the scaled earthquake ground motions. These results demonstrate that the proposed vibration isolator can reduce the response acceleration effectively in a wide range of input frequency and amplitude. Table 5 summarizes the peak response absolute displacements (PRADs) and the peak ground displacements (PGDs). It is seen in Table

3405 that significant reduction was achieved in PRAD to all sine waves. On the other hand,

341 reductions are not observed for the K-Net Ojiya UD records. In fact, the PRADs were amplified by the vibration isolator. Figure 15 shows examples of the time histories of the GA, RA, GD, RAD, RRD for the case of $d=40 \mathrm{~mm}$. The input excitations are S4-4 and O-3. Figure 15 shows that the RAs were reduced sufficiently during the entire 
excitation for both cases. The reduction of the RAD to S4-4 excitation and the

\section{Numerical Simulations}

In this section, numerical simulations are performed to compare their results with the

$40.24 \mathrm{~kg}$, and $48.95 \mathrm{~kg}$ for the cases of $d=60 \mathrm{~mm}, 40 \mathrm{~mm}$, and $20 \mathrm{~mm}$, respectively.

The damping factor $c$ is assumed to be $0.01 \mathrm{Ns} / \mathrm{mm}$ for $d=60 \mathrm{~mm}, 0.04 \mathrm{Ns} / \mathrm{mm}$ for $d=$

$40 \mathrm{~mm}$, and $0.06 \mathrm{Ns} / \mathrm{mm}$ for $d=20 \mathrm{~mm}$. These values are determined by trial and error

to fit the simulations results to the experimental data. To avoid singular points in

numerical simulations, the friction force $q$ is approximated by $q^{*}$, defined as

$$
q^{*}=\left\{\begin{array}{ccc}
-Q & \text { if } & \Delta \dot{w}<-Q / b \\
b \Delta \dot{w} & \text { if } & -Q / b \leq \Delta \dot{w} \leq Q / b, \\
Q & \text { if } & \Delta \dot{w}>Q / b
\end{array}\right.
$$

The slope $b$ is determined as $1 \mathrm{Ns} / \mathrm{mm}$ for all the cases by trial and error as well.

Numerical integrations are performed using the Runge-Kutta method. 
362 simulations with the experimental results when the input excitations are S4-4 and O-3

363 and the value of $d$ is $40 \mathrm{~mm}$. Figure 16 demonstrates that the RA waves obtained from

364 the simulations agree reasonably well with the experimental results.

The PRAs obtained from the experiments and the simulations for the cases of $d=$

60, 40, and $20 \mathrm{~mm}$ are compared in Figure 17, where the input excitations are S2-2,

S3-4, S4-4, S5-4, S6-4, and O-3. For reference, the theoretical prediction of the upper

bound of the response acceleration obtained by using Eq. (17) is plotted by the solid line.

As shown in Figure 17, the theoretical prediction agrees well with the simulation results.

On the other hand, there are a couple of cases where the PRAs obtained from the shaking table tests exceed the theoretical predictions.

Figure 18 compares the response acceleration spectra [30] to study the potential of the measured waves to shake the objects placed on the shaking table and the upper table of the isolator. In the figure, the case of S4-4 and $d=20 \mathrm{~mm}$ where the highest

PRA are measured is investigated and the damping ratio is assumed as $5 \%$. As can be the response acceleration appears mainly in the frequency range higher than $20 \mathrm{~Hz}$. This verifies that the low frequency vibrations, which are important for avoiding large 
380 isolator, although scrutiny of the source of the unintended high-frequency vibrations is

381 still necessary. Backlash and friction in the bearings and pin-connections are potential

382 sources of the unintended high-frequency vibrations.

\section{5. Conclusions}

385 This study has presented a passive vertical vibration isolator with nonlinear restoring 386 force adjustable to the change of the mass of the isolated object. A simple mechanism to 387 change the nonlinear restoring force has been introduced. One of the main features of 388 the present vibration isolator is that quick and easy adjustment is possible when the mass of the isolated object is changed while keeping the peak response acceleration within the same tolerance. The efficacy of the proposed vibration isolator has been demonstrated through shaking table tests and numerical simulations, where the vibration isolator was subjected to sine waves and scaled earthquake ground motions under different values of the mass of the isolated object.

\section{Acknowledgments}

This research was supported by A-STEP program (AS2311091B), provided by the 
398 Kyoto University, helped with the shaking table and quasi-static loading tests. The supports mentioned above are gratefully acknowledged.

401

\section{References}

[1] P. Alabuzhev, A. Gritchin, L. Kim, G. Migirenko, V. Chon, P. Stepanov.

Vibration Protecting and Measuring Systems with Quasi-zero Stiffness.

[2] W.G. Molyneux. The Support of an Aircraft for Ground Resonance Tests: A 30( 6) (1958) 160-166. 84-89.

[4] D.L. Platus. Negative-stiffness-mechanism vibration isolation systems, Proceedings of SPIE Vol. 1619, Vibration Control in Microelectronics, Optics, and Metrology, (1992) 44-54.

[3] S.E. Woodard, J.M. Housner. Nonlinear behavior of a passive zero-spring-rate suspension system, Journal of Guidance, Control, and Dynamics, 14(1), (1991), 
springs in Euler column buckling mode, Physics Letters A, 300 (2002) 122-130.

417 [6] L.N. Virgin, R.B. Davis. Vibration isolation using buckled struts, Journal of Sound and Vibration, 260 (2003) 965-973.

[7] R.H. Plaut, J.E. Sidbury, L.N. Virgin. Analysis of buckled and pre-bent fixed-end columns used as vibration isolators, Journal of Sound and Vibration, 283 (2005) $1216-1228$.

[9] C.-M. Lee, V. Goverdovskiy, A. Temnikov. Design of springs with negative stiffness to improve vehicle driver vibration isolation, Journal of Sound and Vibration, 302 (2007) 865-874.

[10] R. Plaut, H. Favor, A. Jeffers, L. Virgin. Vibration isolation using buckled or pre-bent columns Part 1: Two-dimensional motions of horizontal rigid bar, Journal of Sound and Vibration, 310 (2008) 409-420.

[11] A.E. Jeffers, R.H. Plaut, L.N. Virgin, Vibration isolation using buckled or pre-bent columns - Part 2: Three-dimensional motions of horizontal rigid plate, Journal of Sound and Vibration, 310 (2008) 421-432. 
434 [12] R. Ibrahim. Recent advances in nonlinear passive vibration isolators, Journal of Sound and Vibration, 314 (2008) 371-452.

[13] I. Kovacic, M. J. Brennan, T. P.Waters. A study of a nonlinear vibration isolator with a quasi-zero stiffness characteristic, Journal of Sound and Vibration, 315 (2008) 700-711.

[14] L.N. Virgin, S.T. Santillan, R.H. Plaut. Vibration isolation using extreme geometric nonlinearity, Journal of Sound and Vibration, 315 (2008) 721-731. 2357-2364 (2009) 707-717. and Vibration, 325 (2009) 870-883.

[18] G. Gatti, I. Kovacic, M. J. Brennan. On the response of a harmonically excited two degree-of-freedom system consisting of a linear and a nonlinear quasi-zero 
452

453

454

455

456

457

459

460

461

462

463

464

465

466

467

468

469

stiffness oscillator, Journal of Sound and Vibration, 329 (2010) 1823-1835.

[19] T.D. Le, K.K. Ahn. A vibration isolation system in low frequency excitation region using negative stiffness structure for vehicle seat, Journal of Sound and Vibration, 330 (2011) 6311-6335.

[20] A. Carrella, M.J. Brennan, T.P. Waters, V. Lopes. Force and displacement transmissibility of a nonlinear isolator with high-static-low-dynamic stiffness, International Journal of Mechanical Sciences, 55 (2012) 22-29.

[21] J. Yang, Y.P. Xiong, J.T. Xing. Dynamics and power flow behavior of a nonlinear vibration isolation system with a negative stiffness mechanism, Journal of Sound and Vibration, 332 (2013) 167-183.

[22] A.D. Shaw, S.A. Neild, D.J. Wagg. Dynamic analysis of high static low dynamic stiffness vibration isolation mounts, Journal of Sound and Vibration, 332 (2013) 1437-1455.

[23] A. Carrella, M.J. Brennan, T.P Waters, K. Shin. On the design of a high-static-low-dynamic stiffness isolator using linear mechanical springs and magnets, Journal of Sound and Vibration, 315 (2008) 712-720.

[24] W.S. Robertson, M. Kidner, B.S. Cazzolato, A.C. Zander. Theoretical design parameters for a quasi-zero stiffness magnetic spring for vibration isolation, 
Journal of Sound and Vibration, 326 (2009) 88-103.

[25] M.M. Khan, D.C. Lagoudas, J.J. Mayes, B.K. Henderson. Pseudoelastic SMA spring elements for passive vibration isolation: Part I Modeling, Journal of Intelligent Material Systems and Structures. 15 (2004) 415-441.

[26] Y. Araki, T. Asai, T. Masui. Vertical vibration isolator having piecewise constant restoring force, Earthquake Engineering \& Structural Dynamics, 38 (2009) 1505-1523.

[27] Y. Araki, S. Kawabata, T. Asai, T. Masui. Response of vibration isolated object to ground motions with intense vertical accelerations, Engineering Structures, 33 (2011) 3610-3619.

[28] N. Kikuchi, J.T. Oden, Contact Problems in Elasticity: A Study of Variational Inequalities and Finite Element Methods, SIAM, 1995.

[29] D. Cardone, Re-centering capability of flag-shaped seismic isolation systems, Bulletin of Earthquake Engineering 10 (2012) 1267-1284.

[30] A.K. Chopra, Dynamic of Structures, 4th edition, Prentice Hall, 2011. 
(a)

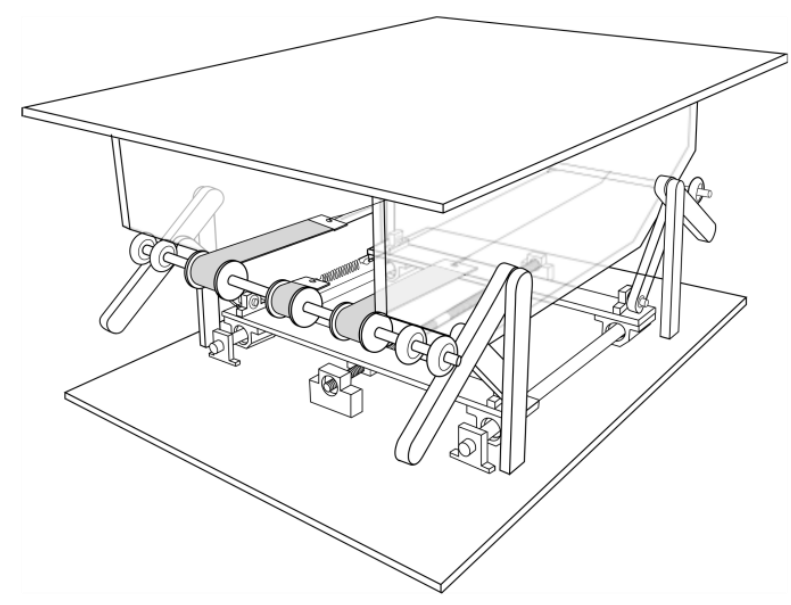

486

487

488

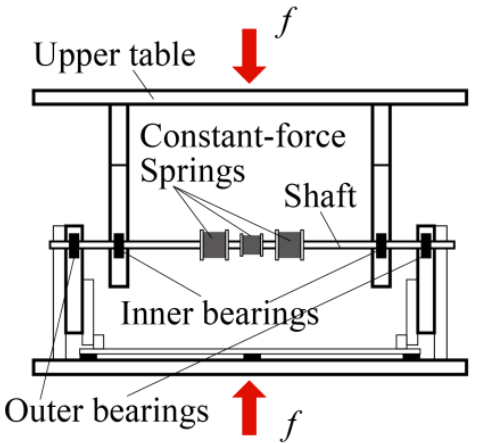

(a)

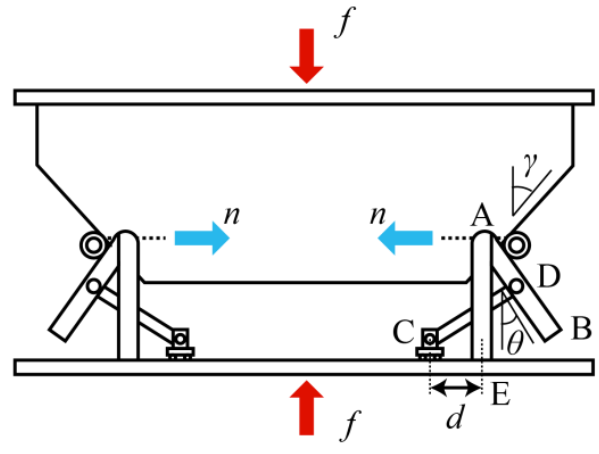

(b)

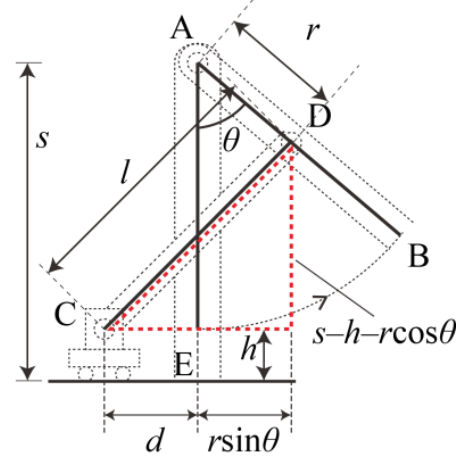

(c)

Figure 2: Schematic illustration of the proposed device. (a) Front side. (b) Lateral side. (c)

Crank. 


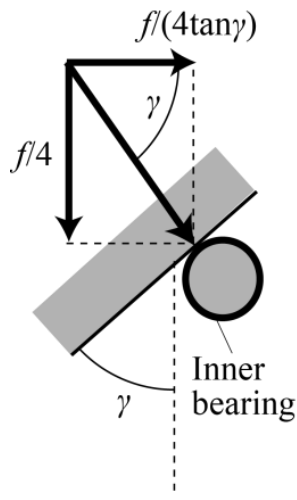

(a)

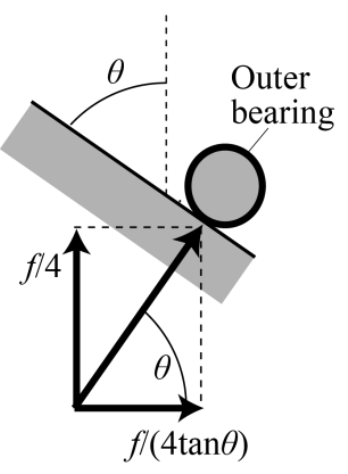

(b)

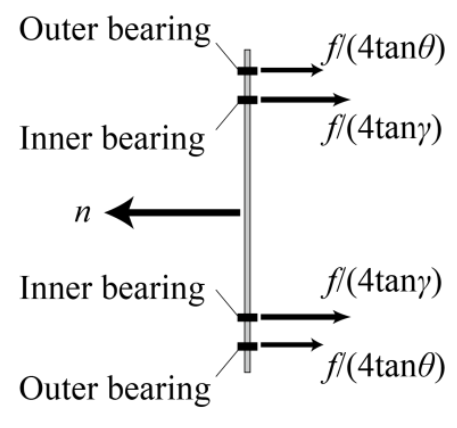

(c)
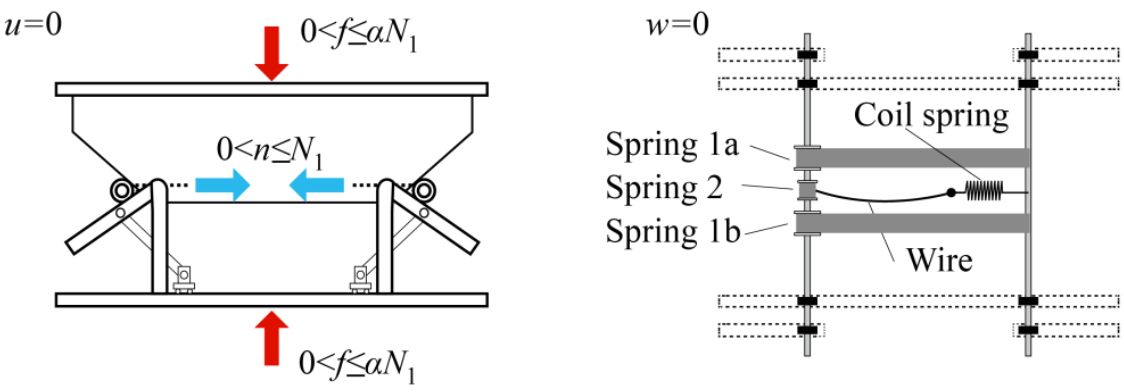
of horizontal forces acting on the right shaft. (b)

(c)
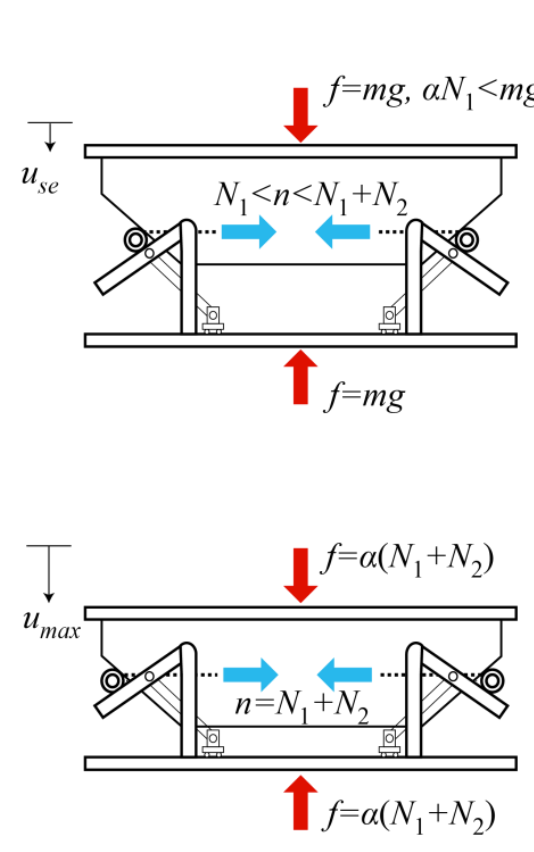

(a)

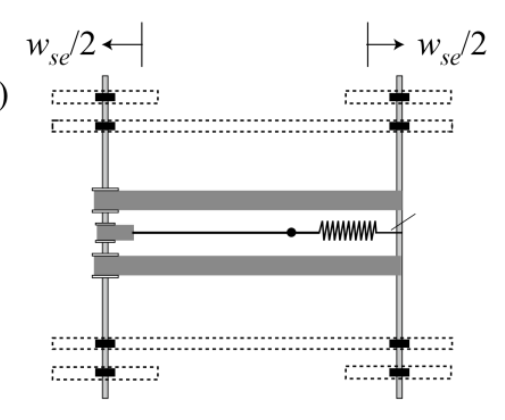

$w_{\max }$

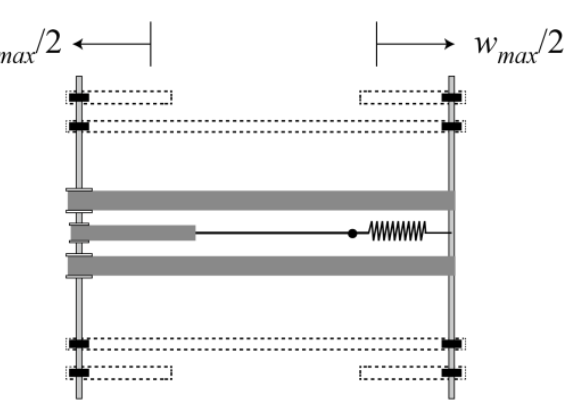

500 Figure 4: Mechanism for producing nonlinear restoring force. (a) Upper limit position. (b) Static equilibrium position. (c) Lower limit position. 


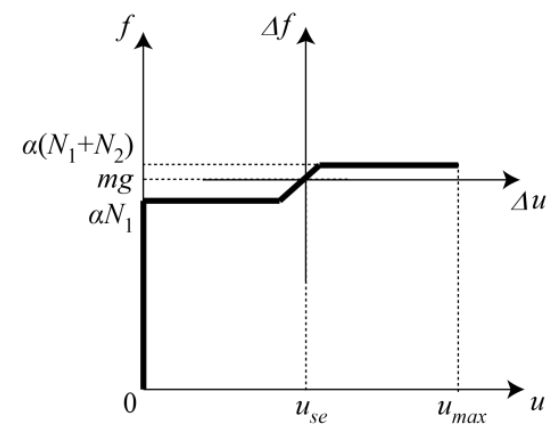

(a)

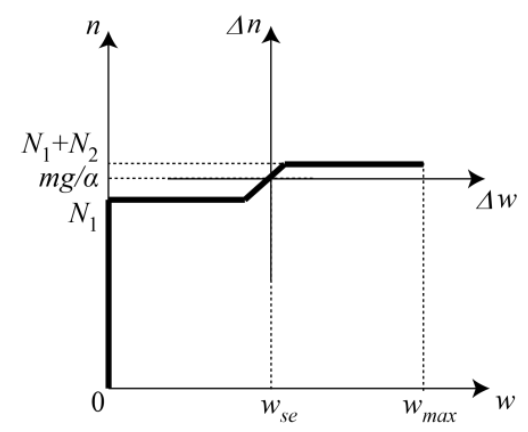

(b)

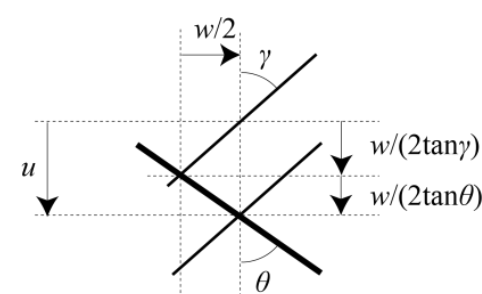

(c)
503

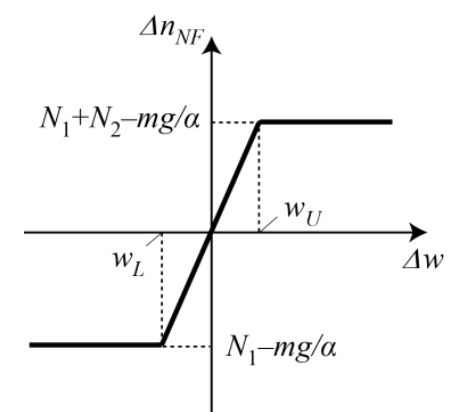

(a)

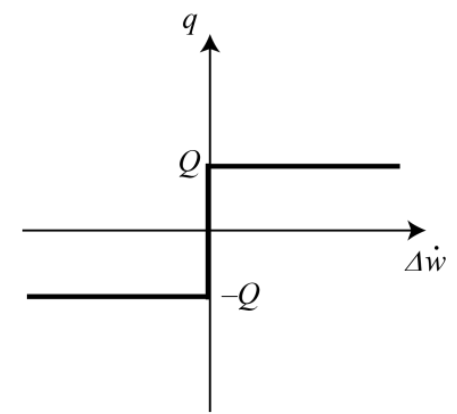

(b)

Figure 6: Numerical models. (a) Restoring force. (b) Friction force.

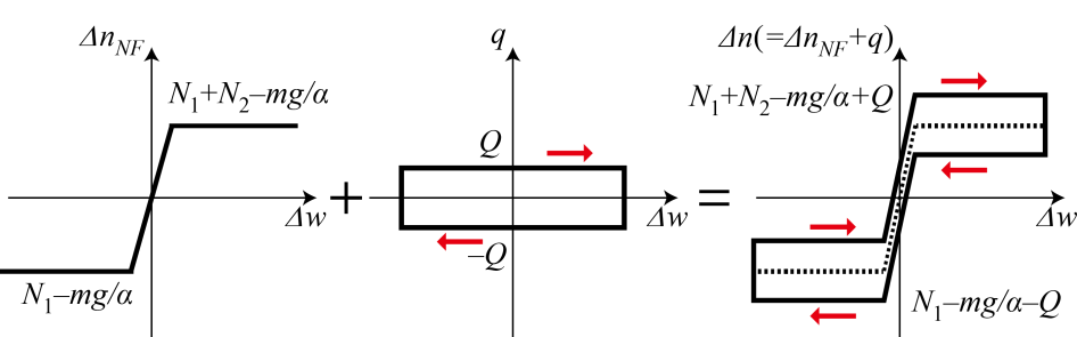

Figure 7: Schematic illustration of the restoring force model including friction. 


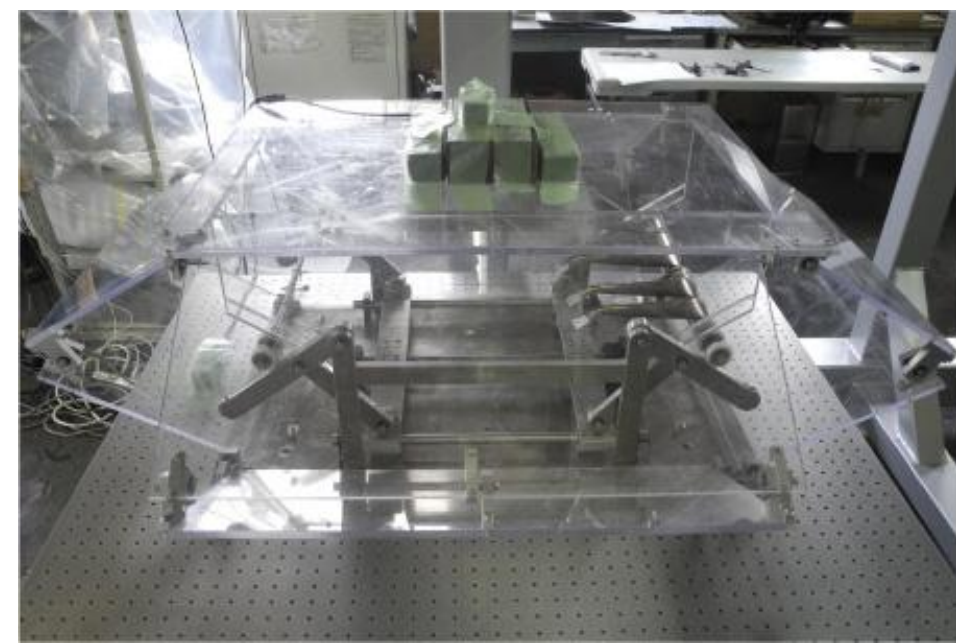

Figure 8: Photograph of a prototype of the vibration isolator.

(a)

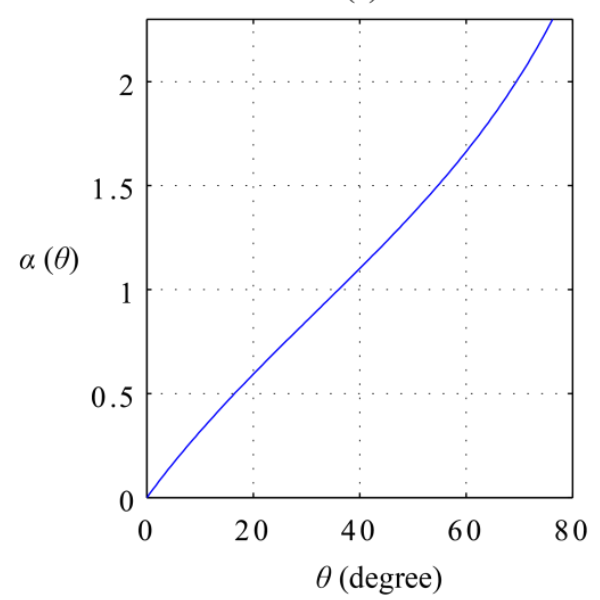

(b)

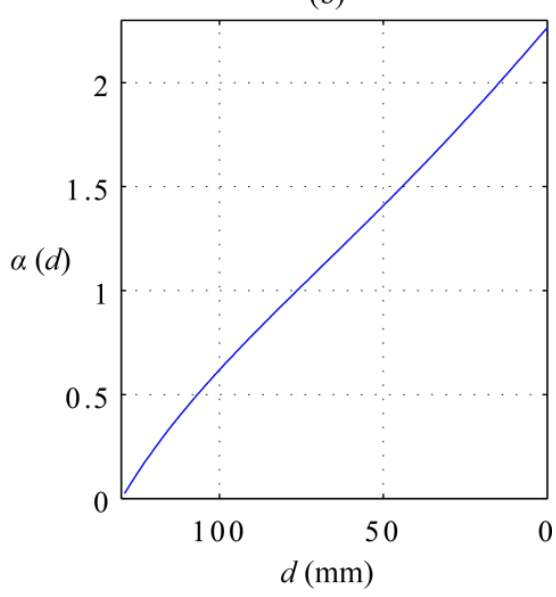

Figure 9: Amplification factor $\alpha$. (a) $\alpha$ of $\theta$. (b) $\alpha$ of $d$. 
(a)

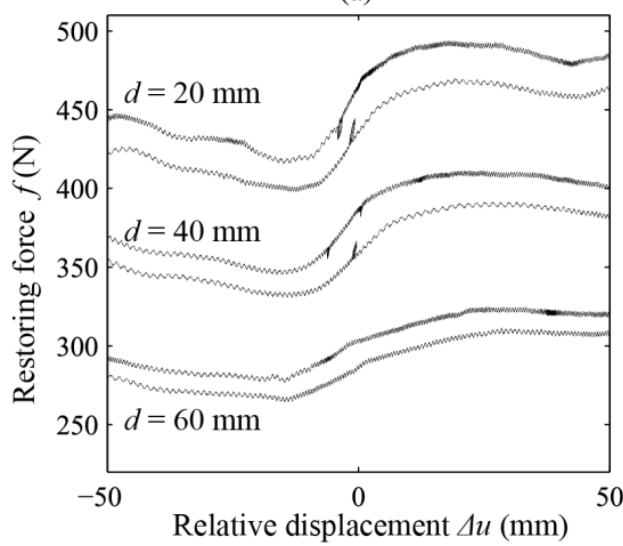

(b)

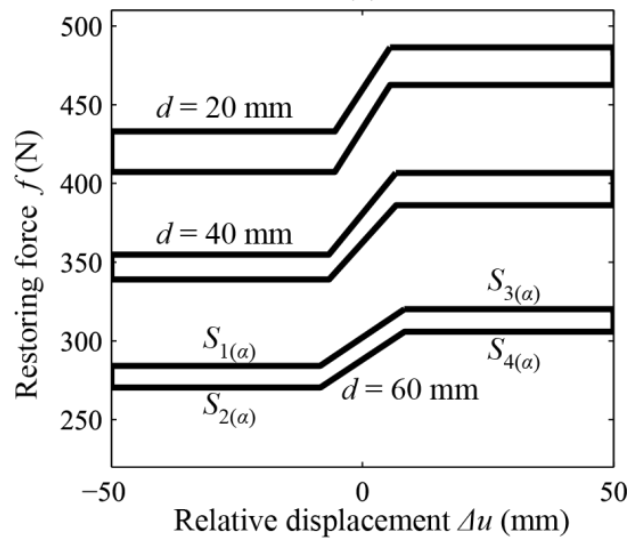

Figure 10: Restoring forces for the cases of $d=60 \mathrm{~mm}, d=40 \mathrm{~mm}$, and $d=20 \mathrm{~mm}$. (a)

Quasi-static loading test results. (b) Numerical models.

(a)

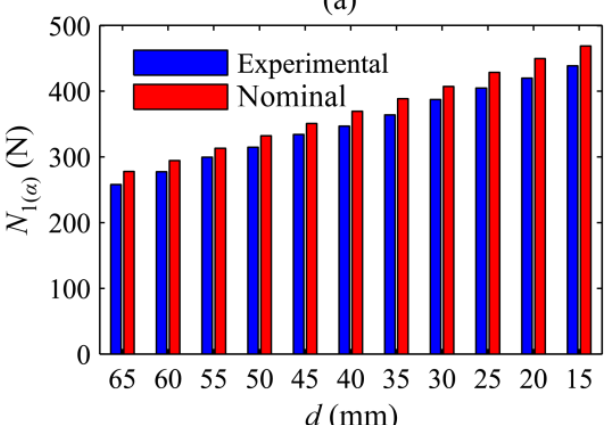

(b)

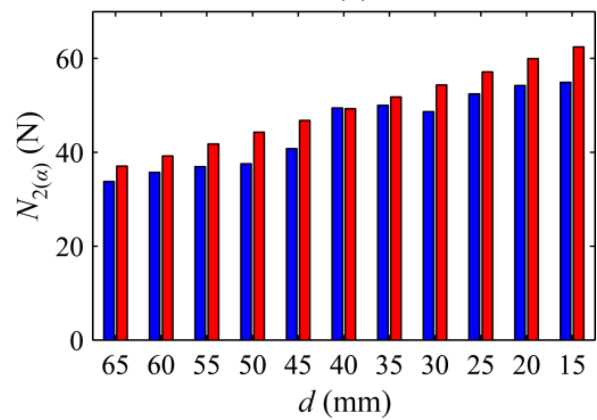

Figure 11: Comparisons between the experimental and nominal capacities of the constant-force springs. (a) $N_{1(\alpha)}$. (b) $N_{2(\alpha)}$.

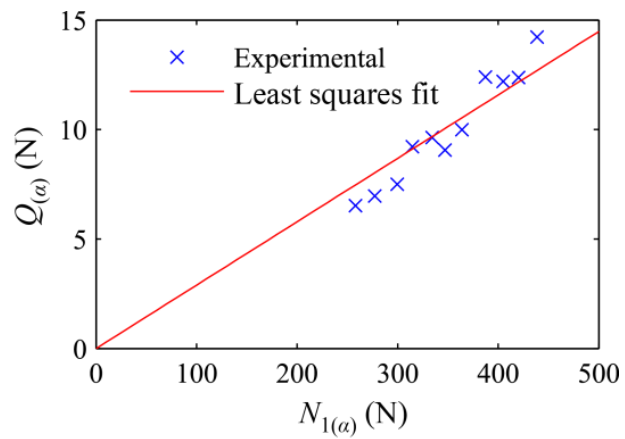




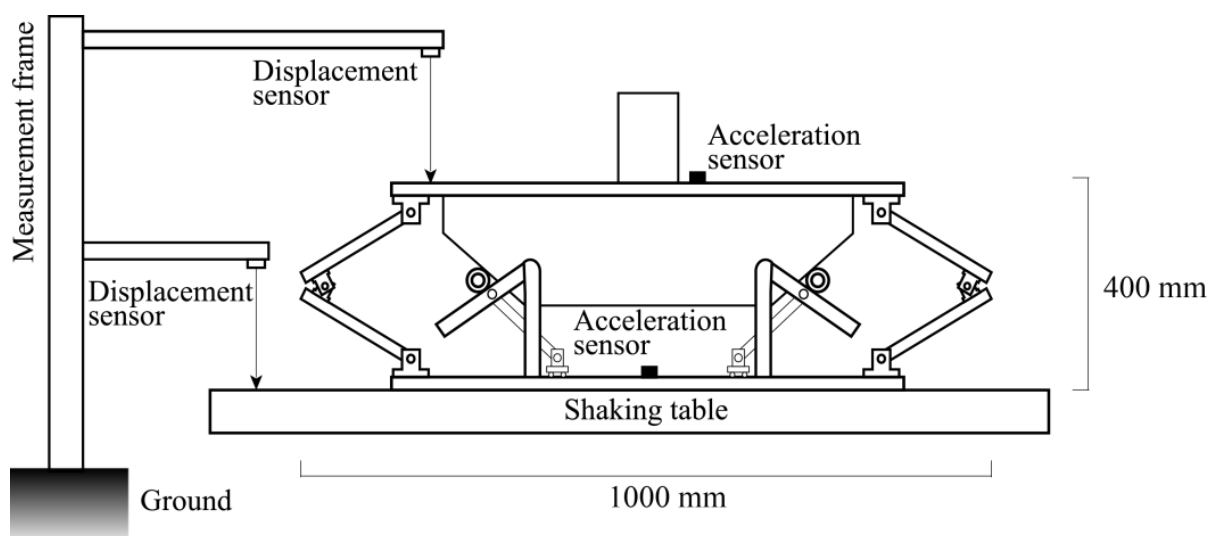

Figure 13: Experimental setup for the shaking table tests.

(a)

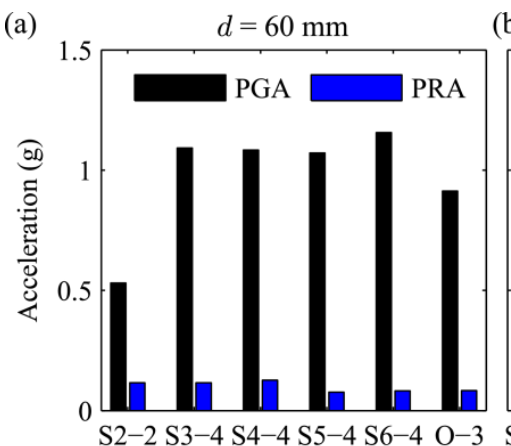

Input excitation (b)

$d=40 \mathrm{~mm}$

(c)

Figure 14: Comparisons of peak accelerations measured in shaking table tests. (a) $d=60 \mathrm{~mm}$.

(b) $d=40 \mathrm{~mm}$. (c) $d=20 \mathrm{~mm}$. 
(a)
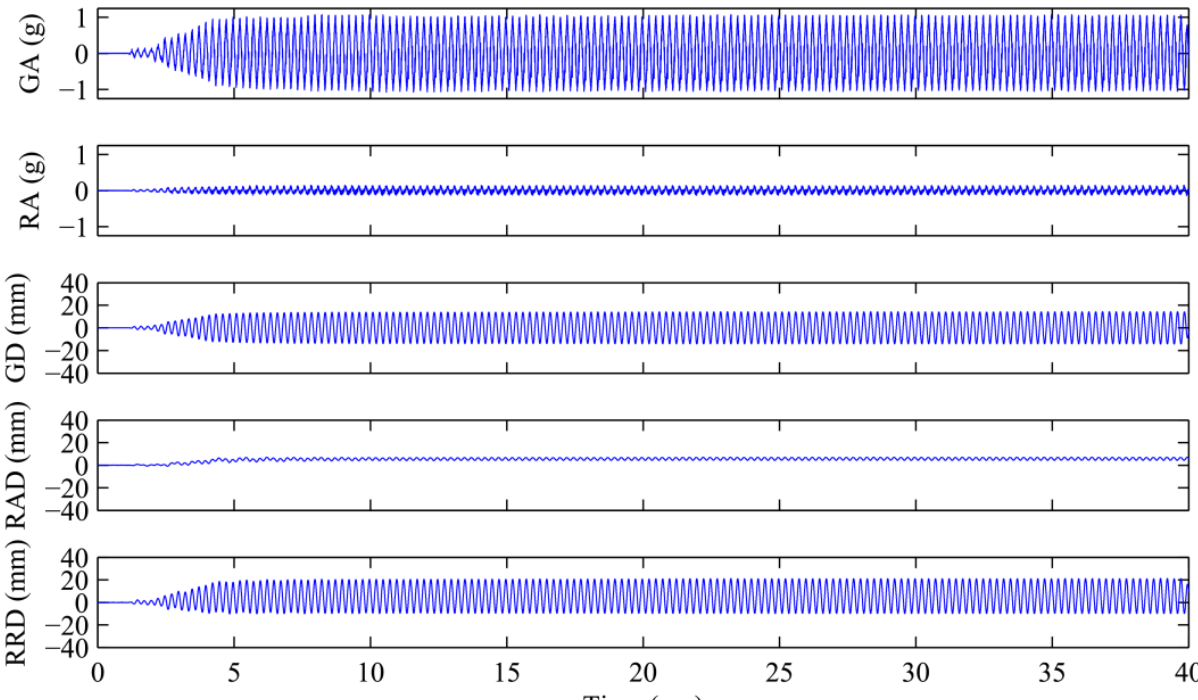

(b)
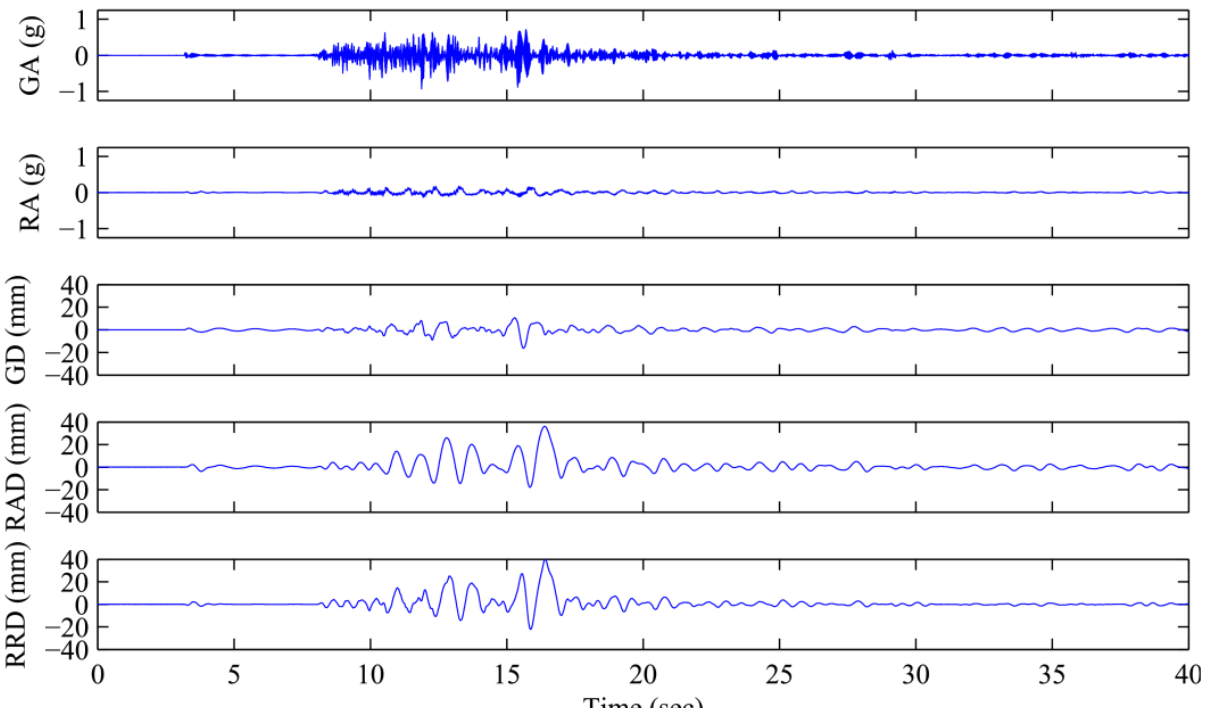

Figure 15: Time histories of shaking table tests for the case of $d=40 \mathrm{~mm}$. (a) S4-4. (b) O-3. 

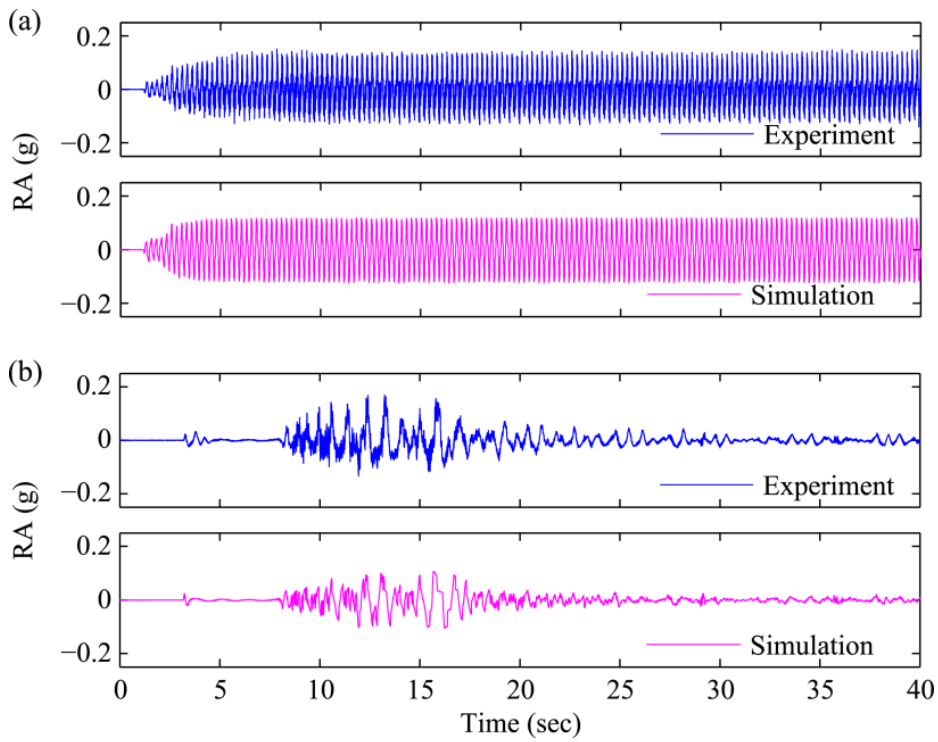

Figure 16: Comparisons of time histories between shaking table tests and simulations for the case of $d=40 \mathrm{~mm}$. (a) S4-4. (b) O-3.

(b)
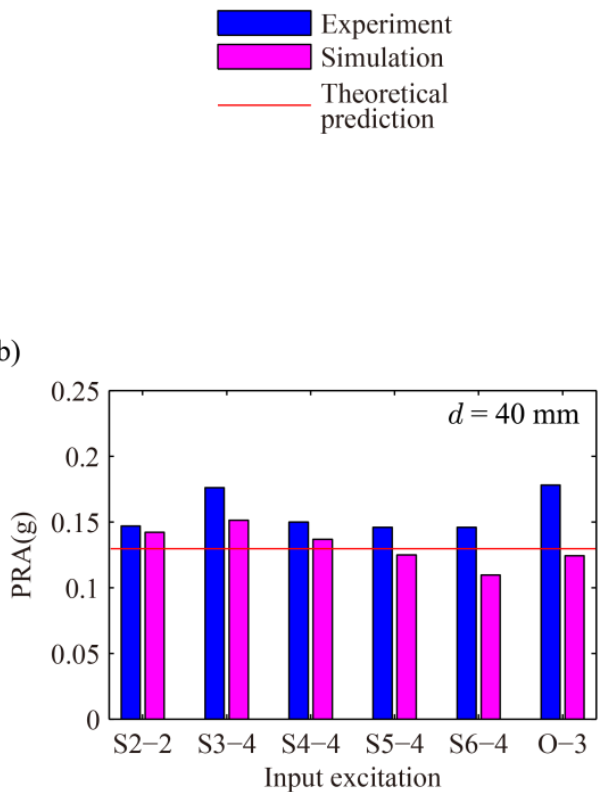

(a)

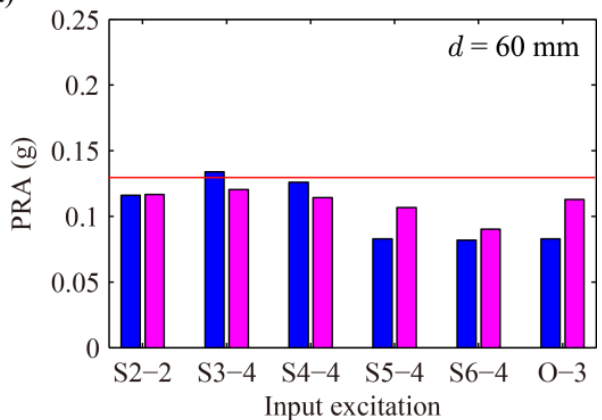

(c)

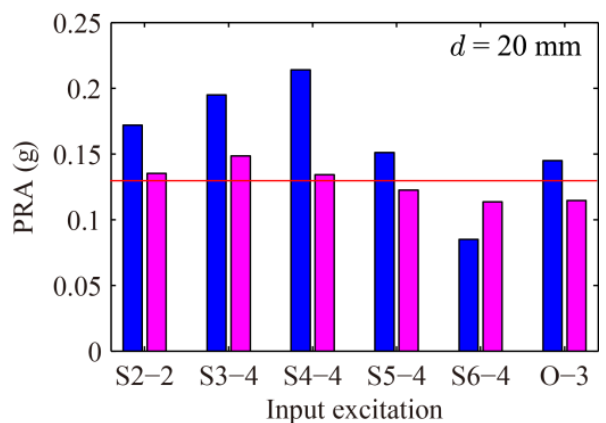

Figure 17: Comparisons of peak response accelerations. (a) $d=60 \mathrm{~mm}$. (b) $d=40 \mathrm{~mm}$. (c) $d=$ 
50

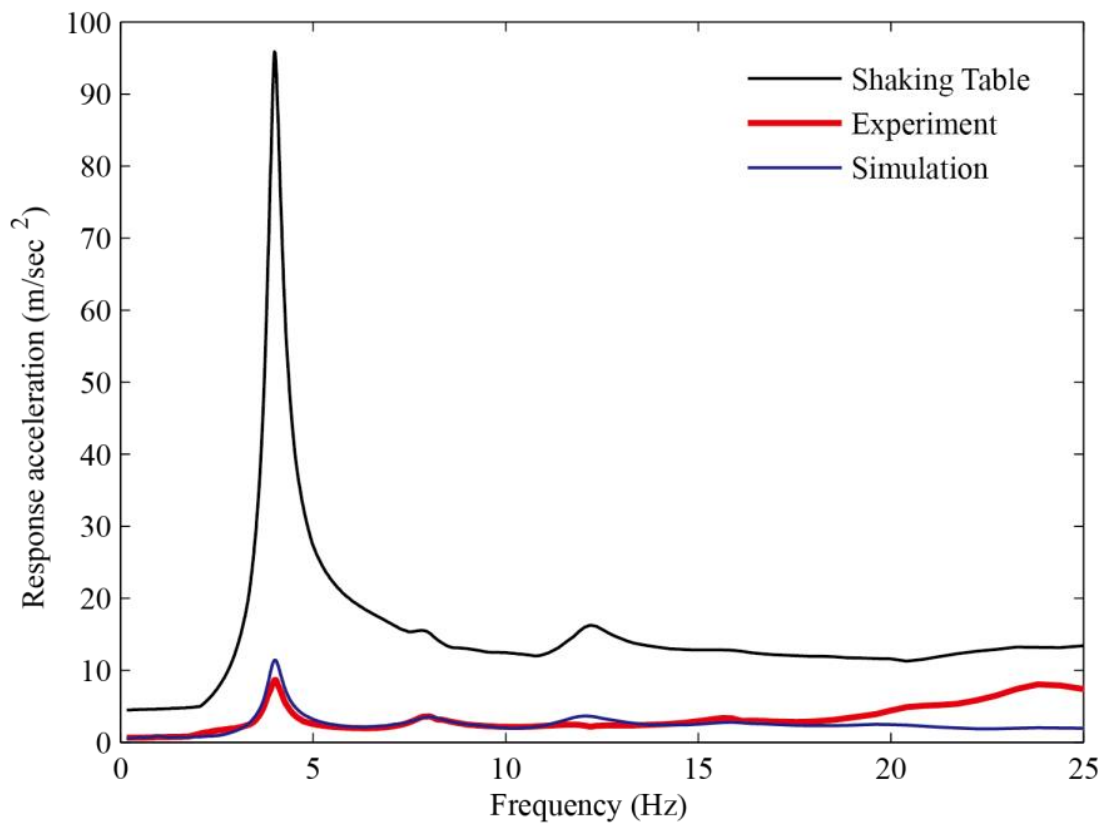

Figure 18: Response acceleration spectra for the case of S4-4 and $d=20 \mathrm{~mm}$.

Table 1: Reference values of parameters.

\begin{tabular}{|c|c|c|c|c|c|c|}
\hline$d(\mathrm{~mm})$ & $\alpha$ & $N_{1(\alpha)}(\mathrm{N})$ & $N_{2(\alpha)}(\mathrm{N})$ & $Q_{(\alpha)}(\mathrm{N})$ & $u_{R(\alpha)}(\mathrm{mm})$ & $k_{(\alpha)}(\mathrm{N} / \mathrm{mm})$ \\
\hline 65 & 1.18 & 277.9 & 37.1 & 8.0 & 17.7 & 2.09 \\
\hline 60 & 1.25 & 294.4 & 39.3 & 8.5 & 16.7 & 2.34 \\
\hline 55 & 1.33 & 313.2 & 41.8 & 9.1 & 15.7 & 2.65 \\
\hline 50 & 1.41 & 332.1 & 44.3 & 9.6 & 14.8 & 2.98 \\
\hline 45 & 1.49 & 350.9 & 46.8 & 10.1 & 14.0 & 3.33 \\
\hline 40 & 1.57 & 369.7 & 49.3 & 10.7 & 13.3 & 3.70 \\
\hline 35 & 1.65 & 388.6 & 51.8 & 11.2 & 12.7 & 4.08 \\
\hline 30 & 1.73 & 407.4 & 54.3 & 11.8 & 12.1 & 4.49 \\
\hline 25 & 1.82 & 428.6 & 57.1 & 12.4 & 11.5 & 4.97 \\
\hline 20 & 1.91 & 468.6 & 60.0 & 13.0 & 11.0 & 5.47 \\
\hline 15 & 1.99 & 449.8 & 62.5 & 13.5 & 10.5 & 5.94 \\
\hline
\end{tabular}

Table 2: Experimental values of parameters.

\begin{tabular}{|l|l|l|l|l|l|l|l|l|}
\hline$d$ & $S_{1(\alpha)}(\mathrm{N})$ & $S_{2(\alpha)}(\mathrm{N})$ & $S_{3(\alpha)}(\mathrm{N})$ & $S_{4(\alpha)}(\mathrm{N})$ & $N_{1(\alpha)}(\mathrm{N})$ & $N_{2(\alpha)}(\mathrm{N})$ & $Q_{(\alpha)}(\mathrm{N})$ & $k_{(\alpha)}$ \\
\hline
\end{tabular}




\begin{tabular}{|c|c|c|c|c|c|c|c|c|}
\hline$(\mathrm{mm})$ & & & & & & & & $(\mathrm{N} / \mathrm{mm})$ \\
\hline 65 & 264.1 & 252.0 & 298.9 & 284.9 & 258.1 & 33.8 & 6.5 & 2.09 \\
\hline 60 & 284.2 & 270.5 & 320.3 & 306.2 & 277.3 & 35.7 & 7.0 & 2.34 \\
\hline 55 & 306.9 & 292.3 & 344.2 & 328.9 & 299.6 & 37.0 & 7.5 & 2.65 \\
\hline 50 & 323.3 & 306.0 & 362.0 & 342.4 & 314.6 & 37.6 & 9.2 & 2.98 \\
\hline 45 & 344.1 & 324.4 & 384.4 & 365.7 & 334.3 & 40.8 & 9.6 & 3.33 \\
\hline 40 & 354.8 & 339.1 & 406.7 & 386.2 & 347.0 & 49.5 & 9.1 & 3.70 \\
\hline 35 & 373.4 & 354.6 & 424.6 & 403.5 & 364.0 & 50.0 & 10.0 & 4.08 \\
\hline 30 & 399.9 & 374.6 & 447.7 & 423.4 & 387.2 & 48.7 & 12.4 & 4.49 \\
\hline 25 & 417.3 & 392.4 & 469.3 & 445.4 & 404.9 & 52.5 & 12.2 & 4.97 \\
\hline 20 & 433.0 & 407.4 & 486.4 & 462.5 & 420.2 & 54.3 & 12.4 & 5.47 \\
\hline 15 & 454.2 & 422.8 & 506.2 & 480.6 & 438.5 & 54.9 & 14.2 & 5.94 \\
\hline
\end{tabular}

Table 3: Input excitations.

\begin{tabular}{|c|c|c||c|c|c|}
\hline Name & Input & $\begin{array}{c}\text { Intended } \\
\text { PGA }(\mathrm{g})\end{array}$ & Name & Input & $\begin{array}{c}\text { Intended } \\
\text { PGA }(\mathrm{g})\end{array}$ \\
\hline S2-1 & 2 Hz sine wave & 0.25 & S5-1 & 5 Hz sine wave & 0.25 \\
\hline S2-2 & $2 \mathrm{~Hz}$ sine wave & 0.50 & S5-2 & 5 Hz sine wave & 0.50 \\
\hline S3-1 & 3 Hz sine wave & 0.25 & S5-3 & 5 Hz sine wave & 0.75 \\
\hline S3-2 & 3 Hz sine wave & 0.50 & S5-4 & 5 Hz sine wave & 1.00 \\
\hline S3-3 & 3 Hz sine wave & 0.75 & S6-1 & 6 Hz sine wave & 0.25 \\
\hline S3-4 & 3 Hz sine wave & 1.00 & S6-2 & 6 Hz sine wave & 0.50 \\
\hline S4-1 & $4 \mathrm{~Hz}$ sine wave & 0.25 & S6-3 & 6 Hz sine wave & 0.75 \\
\hline S4-2 & $4 \mathrm{~Hz}$ sine wave & 0.50 & S6-4 & 6 Hz sine wave & 1.00 \\
\hline S4-3 & $4 \mathrm{~Hz}$ sine wave & 0.75 & O-1 & K-NET Ojiya UD & 0.50 \\
\hline S4-4 & $4 \mathrm{~Hz}$ sine wave & 1.00 & O-2 & K-NET Ojiya UD & 0.75 \\
\hline & & & O-3 & K-NET Ojiya UD & 1.00 \\
\hline
\end{tabular}

Table 4: Comparisons between peak ground accelerations and peak response accelerations (g).

\begin{tabular}{|c|c|c|c|c|c|c|}
\hline$d$ & \multicolumn{2}{|c|}{$60 \mathrm{~mm}$} & \multicolumn{2}{c|}{$40 \mathrm{~mm}$} & \multicolumn{2}{c|}{$20 \mathrm{~mm}$} \\
\hline Excitation & PGA & PRA & PGA & PRA & PGA & PRA \\
\hline S2-1 & 0.261 & 0.073 & 0.274 & 0.130 & 0.257 & 0.122
\end{tabular}




\begin{tabular}{|l|l|l|l|l|l|l|} 
S2-2 & 0.531 & 0.116 & 0.519 & 0.147 & 0.518 & 0.154 \\
\hline S3-1 & 0.261 & 0.054 & 0.300 & 0.082 & 0.271 & 0.108 \\
S3-2 & 0.522 & 0.086 & 0.525 & 0.122 & 0.631 & 0.129 \\
S3-3 & 0.809 & 0.111 & 0.800 & 0.134 & 0.835 & 0.144 \\
S3-4 & 1.092 & 0.116 & 1.073 & 0.148 & 1.159 & 0.158 \\
\hline S4-1 & 0.267 & 0.040 & 0.264 & 0.079 & 0.262 & 0.075 \\
S4-2 & 0.537 & 0.063 & 0.565 & 0.077 & 0.525 & 0.094 \\
S4-3 & 0.808 & 0.088 & 0.830 & 0.116 & 0.817 & 0.160 \\
S4-4 & 1.083 & 0.126 & 1.076 & 0.148 & 1.079 & 0.214 \\
\hline S5-1 & 0.273 & 0.034 & 0.271 & 0.044 & 0.270 & 0.056 \\
S5-2 & 0.535 & 0.046 & 0.529 & 0.068 & 0.532 & 0.087 \\
S5-3 & 0.826 & 0.061 & 0.804 & 0.090 & 0.812 & 0.116 \\
S5-4 & 1.071 & 0.077 & 1.068 & 0.109 & 1.248 & 0.130 \\
\hline S6-1 & 0.299 & 0.034 & 0.262 & 0.061 & 0.260 & 0.055 \\
S6-2 & 0.548 & 0.045 & 0.614 & 0.087 & 0.547 & 0.070 \\
S6-3 & 0.874 & 0.067 & 0.852 & 0.133 & 0.870 & 0.079 \\
S6-4 & 1.156 & 0.082 & 1.166 & 0.146 & 1.240 & 0.084 \\
\hline O-1 & 0.429 & 0.061 & 0.473 & 0.146 & 0.494 & 0.132 \\
O-2 & 0.680 & 0.072 & 0.706 & 0.160 & 0.698 & 0.133 \\
O-3 & 0.913 & 0.083 & 0.960 & 0.178 & 0.968 & 0.144 \\
\hline & & & & & & \\
\hline
\end{tabular}

Table 5: Comparisons between peak ground displacements and peak response absolute displacements $(\mathrm{mm})$.

\begin{tabular}{|c|c|c|c|c|c|c|}
\hline$d$ & \multicolumn{2}{|c|}{$60 \mathrm{~mm}$} & \multicolumn{2}{c|}{$40 \mathrm{~mm}$} & \multicolumn{2}{c|}{$20 \mathrm{~mm}$} \\
\hline Excitation & PGD & PRAD & PGD & PRAD & PGD & PRAD \\
\hline S2-1 & 14.089 & 6.084 & 13.691 & 8.919 & 13.608 & 9.647 \\
S2-2 & 28.213 & 11.744 & 27.947 & 8.106 & 27.831 & 9.931 \\
\hline S3-1 & 6.366 & 1.622 & 6.167 & 2.994 & 6.092 & 3.094 \\
S3-2 & 12.566 & 2.431 & 12.552 & 5.291 & 12.605 & 5.341 \\
S3-3 & 18.883 & 2.569 & 18.700 & 6.697 & 18.661 & 6.981 \\
S3-4 & 25.022 & 6.841 & 24.717 & 6.722 & 24.503 & 6.831 \\
\hline S4-1 & 3.650 & 1.428 & 3.573 & 1.175 & 3.595 & 1.209 \\
S4-2 & 7.250 & 0.894 & 7.223 & 2.784 & 7.209 & 2.509 \\
S4-3 & 10.923 & 1.219 & 10.636 & 4.550 & 10.863 & 3.806
\end{tabular}




\begin{tabular}{|l|c|c|c|c|c|c|} 
S4-4 & 14.552 & 1.922 & 14.248 & 7.138 & 14.475 & 4.650 \\
\hline S5-1 & 2.341 & 0.913 & 2.327 & 0.613 & 2.338 & 0.691 \\
S5-2 & 4.711 & 1.116 & 4.763 & 1.034 & 4.694 & 1.206 \\
S5-3 & 7.141 & 1.319 & 7.081 & 1.641 & 7.128 & 2.066 \\
S5-4 & 9.358 & 1.456 & 9.313 & 2.384 & 11.006 & 2.347 \\
\hline S6-1 & 1.677 & 0.344 & 1.641 & 0.406 & 1.663 & 0.378 \\
S6-2 & 3.325 & 0.453 & 3.320 & 0.528 & 3.319 & 0.491 \\
S6-3 & 5.009 & 0.469 & 5.000 & 0.978 & 4.994 & 1.066 \\
S6-4 & 6.586 & 0.563 & 7.027 & 1.228 & 6.630 & 1.550 \\
\hline O-1 & 8.163 & 12.378 & 8.345 & 21.709 & 12.084 & 28.863 \\
O-2 & 12.175 & 13.300 & 12.267 & 32.478 & 12.170 & 28.922 \\
O-3 & 16.297 & 17.122 & 16.322 & 35.975 & 16.211 & 30.013 \\
\hline
\end{tabular}

